\title{
Thin-walled building structures with improved properties for high-rise construction
}

\author{
Valentina Solovyova ${ }^{1}$, Makhmud Abu-Khasan ${ }^{1, *}$, and Dmitry Solovyov ${ }^{1}$ \\ ${ }^{1}$ Emperor Alexander I St.-Petersburg State Transport University (PGUPS), Moskovsky pr. 9, St.- \\ Petersburg, 190031, Russia
}

\begin{abstract}
A high-efficient complex reactive composition consisting of a polycarboxylate polymer, cesium nitrate $\left(\mathrm{CsNO}_{3}\right)$ and silica sol was developed for cast-in-place housing construction from high-strength concrete. The use of this composition provides production of high-strength concrete with increased crack resistance.
\end{abstract}

\section{Introduction}

One of the tasks of the present is high-rise construction which will have a positive impact on the housing problem solution, especially in big cities of the country. Such objects require reinforced concrete elements with increased reliability which at the same time would be remarkable for lightness, fineness and would not exert excessive pressure on foundation of a structure [1-10].

The solution of this problem can be achieved by producing and using high-strength concrete, e.g. concrete of class B60 and above. It is preferable that concrete has not only increased strength but also improved crack resistance and durability. When applying such a unique concrete, it is possible to manufacture and use thin-walled structures. Their distinguishing feature is the small size, e.g. thickness, compared with two other sizes.

The use of thin-walled structures in construction is quite effective as the mass of a reinforced concrete structure can be reduced more than $25 \%$. At the same time consumption of expensive reinforcement decreases, as well as labor intensity and the total construction cost go down.

One of the techniques to produce high-strength multifunctional concrete is effective chemical activation, which would allow to implement cast-in-place construction.

The chemical activation is supposed:

1. to improve degree of Portland cement mineral hydration, i.e. more molecules of Portland cement's main minerals would be involved in hydration processes;

2. to form an increased amount of low-solubility complex hydrate compounds characterized by improved strength and a certain structure;

3. to increase rate of hydration, especially at an early age which is of fundamental importance for cast-in-place construction.

In order to increase degree of hydration it may be reasonable to consider the use of electrolytes having different nature. Most of their ions are characterized by hypermobility

\footnotetext{
*Corresponding author: pgups1967@mail.ru
} 
and, as a result, they are able to penetrate into particles of Portland cement to disperse them. Thus, more molecules of Portland cement minerals can have chemical interaction with water [11-17].

\section{Methods}

Taking into account this theoretical assumption, effects of various electrolytes on hydration activity of cement was studied, their efficiency having been evaluated by compressive strength index. For this purpose fine concrete of class B40 was produced and then it was used to make samples of beams with dimensions $4 \times 4 \times 16 \mathrm{~cm}$.

During the study plain Portland cement PC500 DO and mortar sand with $\mathrm{M}_{\mathrm{f}}=2,6$ (where: $\mathrm{M}_{\mathrm{f}}$ is fineness modulus) were used in accordance with GOST 8736-2014.

\section{The experiment and its results}

$5 \%$ solution of the electrolytes used in the work was injected into the concrete mix because with this concentration ion velocity has its maximum value.

The results of the studies carried out are presented in the Table 1.

Table 1. Evaluation of the electrolytes' effectiveness.

\begin{tabular}{|c|c|c|c|c|c|c|c|c|c|}
\hline \multirow[b]{3}{*}{ № } & \multirow{3}{*}{ 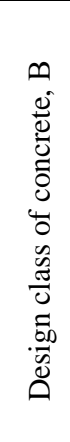 } & \multicolumn{5}{|c|}{ Composition of concrete per $1 \mathrm{~m}^{3}, \mathrm{~kg}$} & \multicolumn{2}{|c|}{$\begin{array}{c}\text { Strength at the } \\
\text { age of } 28 \text { days, } \\
\text { MPa }\end{array}$} & \multirow{3}{*}{ 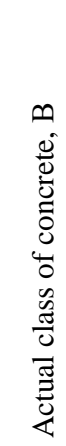 } \\
\hline & & \multirow{2}{*}{ 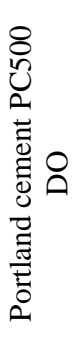 } & \multirow{2}{*}{ 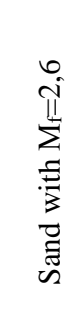 } & \multicolumn{2}{|c|}{ Additive* } & \multirow[b]{2}{*}{ 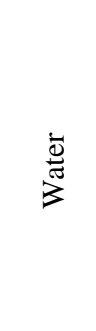 } & \multirow[b]{2}{*}{ 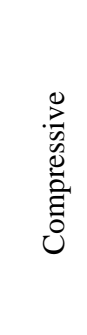 } & \multirow[b]{2}{*}{$\begin{array}{l}\frac{0}{\bar{v}} \\
\stackrel{0}{\oplus}\end{array}$} & \\
\hline & & & & 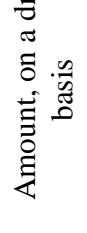 & 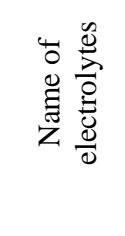 & & & & \\
\hline 1 & 2 & 3 & 4 & 5 & 6 & 7 & 8 & 9 & 10 \\
\hline 1 & 40 & 550 & 1380 & - & - & 270 & 53,6 & 6,20 & 40 \\
\hline 2 & 40 & 550 & 1375 & 5,5 & $\mathrm{LiCl}$ & $160 * *$ & 62,7 & 7,20 & 45 \\
\hline 3 & 40 & 550 & 1375 & 5,5 & $\mathrm{NaCl}$ & 160 & 64,0 & 7,35 & 45 \\
\hline 4 & 40 & 550 & 1375 & 5,5 & $\mathrm{KCl}$ & 160 & 65,1 & 7,44 & 50 \\
\hline 5 & 40 & 550 & 1375 & 5,5 & $\mathrm{CsCl}$ & 160 & 65,9 & 7,5 & $\mathrm{~B} 50$ \\
\hline 6 & 40 & 550 & 1375 & 5,5 & $\mathrm{LiNO}_{3}$ & 160 & 63,8 & 7,35 & 45 \\
\hline 7 & 40 & 550 & 1375 & 5,5 & $\mathrm{Nas} \mathrm{NO}_{3}$ & 160 & 65,4 & 7,5 & 50 \\
\hline 8 & 40 & 550 & 1375 & 5,5 & $\mathrm{KNO}_{3}$ & 160 & 66,3 & 7,6 & 50 \\
\hline 9 & 40 & 550 & 1375 & 5,5 & $\mathrm{C}_{5} \mathrm{NO}_{3}$ & 160 & 67,0 & 7,7 & B50 \\
\hline
\end{tabular}

* According to preliminary studies the rational amount of an electrolyte is $1 \%$ of cement mass.

** 110 liters of water is additionally injected with 5\% solution of an electrolyte.

Analysis of the data from the Table 1 shows that as the radius of a cation increases in the following sequence,

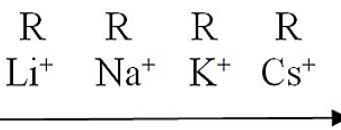

Fig. 1. The radius of a cation increases. 
there is a greater increase in concrete strength irrespective of an anion used. It should be noted that an effect of $\mathrm{NO}_{3}$ anion-based electrolytes is higher than that of $\mathrm{Cl}^{-}$ion-based ones.

This experimental observation correlates with the index of higher cation velocity. Since their radius increases mobility of $\mathrm{NO}_{3}$ anions raises compared with $\mathrm{Cl}^{-}$anions. As a result of the increased velocity of electrolyte particles, they penetrate into conglomerates of Portland cement minerals, dispersing them and, thus, involving the maximum amount of Portland cement minerals in hydration processes.

To confirm the data obtained and substantiate the theoretical assumption comparative physical and chemical studies of the check composition and compositions in the presence of the electrolytes used were also carried out by means of X-ray diffraction and differential thermal analysis methods.

Comparative analysis of the diffraction patterns of the hardened samples of the check composition and compositions with the electrolytes showed that during hardening of all analyzed samples of fine concrete one could observe the formation of hydrosilicates like tobermorite, e.g. $\mathrm{C}_{S} \mathrm{H}(\mathrm{I})$, which is characterized by $\mathrm{d} / \mathrm{n}=(3,07,2.80,1.83) 10^{-10} \mathrm{~m}$ (where: $\mathrm{d} / \mathrm{n}$ is d-space). Besides, the formation of such portlandite as $\mathrm{Ca}(\mathrm{OH})_{2}$ with $\mathrm{d} / \mathrm{n}=(4.93,2.63$, 1.93) $10^{-10} \mathrm{~m}$ was detected, as well as a phase represented by hexaqua calcium aluminate hydrate, $3 \mathrm{CaO} 6 \mathrm{H}_{2} \mathrm{O}$, with $\mathrm{d} / \mathrm{n}=(5.14,2.30,2.23) 10^{-10} \mathrm{~m}$ [26-30].

It was determined that new phases were not found on the diffraction patterns of the samples of fine concrete with the electrolytes but the amount of such a tobermorite-like hydrosilicate as $\mathrm{C}_{\mathrm{S}} \mathrm{H}(\mathrm{I})$ and portlandite is significantly increased, especially in the presence of $\mathrm{KCl}$ and $\mathrm{C}_{\mathrm{S}} \mathrm{Cl}$, as well as $\mathrm{KNO}_{3}$ and $\mathrm{C}_{5} \mathrm{NO}_{3}$ compared with the check sample.

The formation of these phases was also confirmed by differential thermal studies. The $\mathrm{C}_{\mathrm{S}} \mathrm{H}(\mathrm{I})$ hydrosilicate is characterized by the large endothermic effect in the temperature range $180-2600^{\circ} \mathrm{C}$. The formation of portlandite, $\mathrm{Ca}(\mathrm{OH})_{2}$, was established by the presence of the endothermic effect in the temperature range $520-540^{\circ} \mathrm{C}$ which resulted from dehydration of $\mathrm{Ca}(\mathrm{OH})_{2}$ with transition to $\mathrm{CaO}$. The large endothermic effect which was found at a temperature $335^{\circ} \mathrm{C}$ refers to $3 \mathrm{CaO} \mathrm{Al}_{2} \mathrm{O}_{3} 6 \mathrm{H}_{2} \mathrm{O}$ dehydration.

The results presented in the Table 1 and the physical and chemical study data have the same character of changes, namely: gain in compressive strength has taken place with an increase in the radius of a cation. At the same time the amount of formed hydrosilicates such as $\mathrm{C}_{\mathrm{S}} \mathrm{H}(\mathrm{I})$ and the amount of $\mathrm{Ca}(\mathrm{OH})_{2}$ raise. This indicates an increase in degree of hydration of tricalcium silicate, $3 \mathrm{CaO} \mathrm{SiO}$, probably, due to dispersion of conglomerates. The ratio of tensile strength in bending to compressive strength which the samples of both the check composition and the composition in the presence of the electrolytes have is equal because of the formation of the same hydrate compounds and the absence of new phases.

To increase crack resistance of a material it is necessary that during concrete hardening new hydrate phases having a fibrous or acicular structure are synthesized which would have a micro-reinforcing effect on the concrete structure that is formed when hardening. These products can be classified as low-basic calcium hydrosilicates.

To form hydrosilicates with an increased $\mathrm{SiO}_{2}$ content it is expedient to inject reactive $\mathrm{SiO}_{2}$ particles into a hardening system. For this purpose it is proposed to use silica sol because it contains $\mathrm{SiO}_{2} \mathrm{nH}_{2} \mathrm{O}$ nanoparticles.

In this study the effectiveness of the sol in the presence of a highly effective electrolyte such as cesium nitrate, $\mathrm{C}_{5} \mathrm{NO}_{3}$, was evaluated. The effectiveness of the sol was determined by varying compressive strength, tensile strength in bending and fracture toughness index of fine concrete. In the study a colloidal solution of silicic acid, $\mathrm{SiO}_{2} \mathrm{nH}_{2} \mathrm{O}$, having $\mathrm{pH}=3,5$ and $\mathrm{p}=1,014 \mathrm{~g} / \mathrm{cm}^{3}$ (where: $\mathrm{p}$ is density) was used as the sol.

The results of the study are given in the Table 2. 
Table 2. Evaluation of the effectiveness of the combined action of silica sol, $\mathrm{SiO}_{2} \mathrm{nH}_{2} \mathrm{O}$ and the electrolyte, $\mathrm{CsNO}_{3}$.

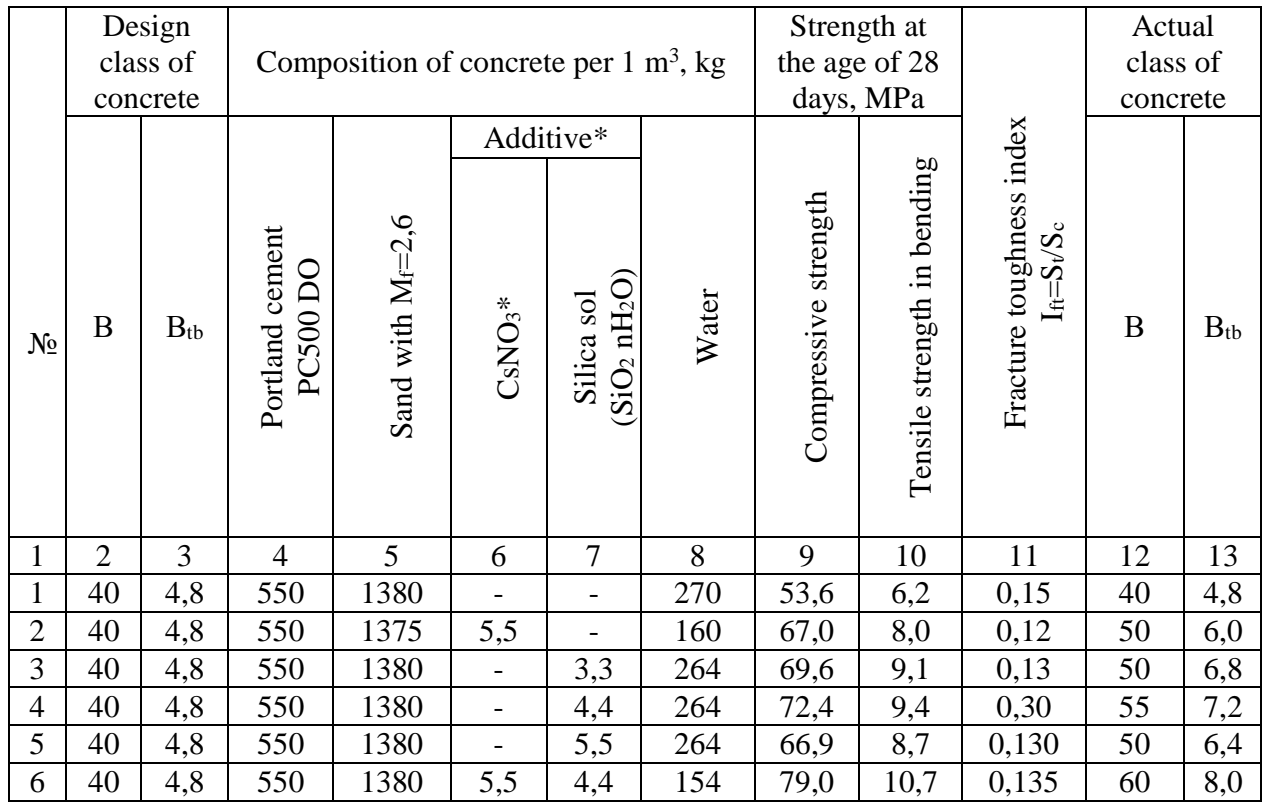

* The electrolyte is injected in the form of $5 \%$ solution; the table indicates its amount on a dry basis.

Analysis of the data from the Table 2 shows that silica sol has a high reactivity and when it is applied an enhancement of tensile strength in bending advances gain in compressive strength. This results in an increase of high-strength concrete's fracture toughness index to a value of $\mathrm{I}_{\mathrm{ft}}=0,13$ which exceeds the regulatory requirements of GOST 10180-2012.

It was experimentally established that when both the electrolyte of cesium nitrate, $\mathrm{C}_{\mathrm{S}} \mathrm{NO}_{3}$, and silica sol, $\mathrm{SiO}_{2} \mathrm{nH}_{2} \mathrm{O}$ are simultaneously present, gain in compressive strength has taken place by $47 \%$. This corresponds to concrete's gain in compressive strength by 2 classes, from B40 to B60. An enhancement of tensile strength in bending exceeds gain in compressive strength and is $72 \%$. This corresponds to a change of tensile strength in bending of concrete's class, from $\mathrm{B}_{\mathrm{tb}} 4,8$ to $\mathrm{B}_{\mathrm{tb}} 8,0$. The improvement of this parameter is of fundamental importance, especially for high-strength concrete as its crack resistance and its stress-stain behavior increase.

According to the results of physical and chemical studies it was fixed that in the presence of silicon system's sol hydration products have a new phase. It is represented by low-basic calcium hydrosilicate such as okenite $\mathrm{CaO} \cdot 2 \mathrm{SiO}_{2} \cdot 2 \mathrm{H}_{2} \mathrm{O}(\mathrm{d} / \mathrm{n}=3,5 ; 2,93 ; 1,80) 10^{-10}$ $\mathrm{m}$, its hardness by Mohs being 5. Besides, it was noted that the formation of nekoite, $3 \mathrm{CaO} \cdot 6 \mathrm{SiO}_{2} \cdot 8 \mathrm{H}_{2} \mathrm{O}(\mathrm{d} / \mathrm{n}=9,23 ; 3,34 ; 2,47) \cdot 10^{-10} \mathrm{~m}$ takes pace, its crystals having a felted structure.

The formation of these products is also confirmed by the results of differential thermal studies, namely: the endothermic effect at a temperature of $718^{\circ} \mathrm{C}$ corresponds to dehydration of okenite, $\mathrm{CaO} 2 \mathrm{SiO}_{2} 2 \mathrm{H}_{2} \mathrm{O}$, the endothermic effect at $732^{\circ} \mathrm{C}$ is related to dehydration of nekoite, $3 \mathrm{CaO} 6 \mathrm{SiO}_{2} 8 \mathrm{H}_{2} \mathrm{O}$, and the endothermic effect at $776^{0} \mathrm{C}$ refers to crystalline modification of dehydrated nekoite. There is completely no portlandite, $\mathrm{Ca}(\mathrm{OH})_{2}$, in the products of hydration of hardened fine concrete modified with an additive which consists of the electrolyte, $\mathrm{C}_{\mathrm{S}} \mathrm{NO}_{3}$, and silica sol, $\mathrm{SiO}_{2} \mathrm{nH}_{2} \mathrm{O}$.

A significant increase in strength of fine concrete with combined effects of the electrolyte, $\mathrm{C}_{\mathrm{S}} \mathrm{NO}_{3}$, and sol, $\mathrm{SiO}_{2} \cdot \mathrm{nH}_{2} \mathrm{O}$, is caused by a rise in degree of hydration due to 
the involvement of more molecules of Portland cement's main minerals in reactions of their interaction with water and the formation of new phases which have different fiber structure and increased hardness. This had a positive effect on an enhancement of tensile strength in bending. Flowability of concrete mix is known to be of fundamental importance in cast-inplace construction. In order to improve concrete consistency and, as a result, to increase the density of a hardened stone and, therefore, its durability one should add effective surface active agents to the proposed reactive composition. Modern polycarboxylate polymers based on methacrylic acid and ethyl methacrylate which have a branched structure with an average length of side chains can be used as such surface active agents.

It was experimentally established that when using this surface active agent in the presence of the developed reactive composition, flowability of the concrete mixture was more than 5 times higher. To achieve the required fluidity of concrete it was necessary to reduce water content. Taking into account plasticizing effects of the polycarboxylate polymer, an activating effect of the complex reactive composition was evaluated.

The results of the studies one can see in the Table 3.

Table 3. Evaluation of the effectiveness of the complex reactive composition action.

\begin{tabular}{|c|c|c|c|c|c|c|c|c|c|c|c|c|}
\hline \multirow[b]{3}{*}{ № } & \multicolumn{2}{|c|}{$\begin{array}{l}\text { Design } \\
\text { class of } \\
\text { concrete }\end{array}$} & \multicolumn{6}{|c|}{ Composition of concrete per $1 \mathrm{~m}^{3}, \mathrm{~kg}$} & \multicolumn{2}{|c|}{$\begin{array}{c}\text { Strength at the } \\
\text { age of } 28 \\
\text { days, MPa }\end{array}$} & \multicolumn{2}{|c|}{$\begin{array}{c}\text { Actual } \\
\text { class of } \\
\text { concrete, }\end{array}$} \\
\hline & \multirow[b]{2}{*}{ B } & \multirow[b]{2}{*}{$\mathrm{B}_{\mathrm{tb}}$} & \multirow[b]{2}{*}{ 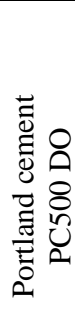 } & \multirow[b]{2}{*}{ 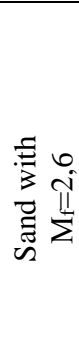 } & \multicolumn{3}{|c|}{ Additive* } & \multirow[b]{2}{*}{$\frac{\bar{v}}{\bar{\pi}}$} & \multirow[b]{2}{*}{ 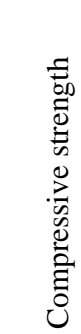 } & \multirow[b]{2}{*}{ 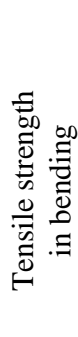 } & \multirow[b]{2}{*}{ B } & \multirow[b]{2}{*}{$\mathrm{B}_{\mathrm{tb}}$} \\
\hline & & & & & ¿n & 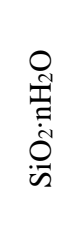 & 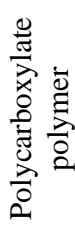 & & & & & \\
\hline 1 & 40 & 4,8 & 550 & 1380 & - & - & - & 270 & 53,6 & 6,2 & 40 & 4,8 \\
\hline 2 & 40 & 4,8 & 550 & 1375 & 5,5 & 4,4 & - & 154 & 79,9 & 10,7 & 60 & 8,0 \\
\hline 3 & 40 & 4,8 & 550 & 1380 & - & - & 4,4 & 210 & 66,7 & 8,0 & 50 & 6,0 \\
\hline 4 & 40 & 4,8 & 550 & 1380 & - & - & 5,5 & 208 & 68,2 & 8,1 & 50 & 6,0 \\
\hline 5 & 40 & 4,8 & 550 & 1380 & - & - & 6,6 & 206 & 67,4 & 8,1 & 50 & 6,0 \\
\hline 6 & 40 & 4,8 & 550 & 1375 & 5,5 & 4,4 & 5,5 & 206 & 85,5 & 10,9 & 65 & 8.0 \\
\hline
\end{tabular}

* The electrolyte is injected in the form of $5 \%$ solution; the table indicates its amount on a dry basis.

\section{Discussion}

In the presence of the developed complex reactive composition consisting of a polycarboxylate polymer, cesium nitrate electrolyte and silica sol additional gain in compressive strength is observed. This has made it possible to increase compressive strength index by $60 \%$ and to ensure production of effective high-strength concrete of class B65. These results can be explained with the reference to proceedings [18-23].

\section{Conclusions}

1. An effective reactive composition consisting of a polycarboxylate polymer, cesium nitrate electrolyte, $\mathrm{CsNO}_{3}$, and a silica sol, $\mathrm{SiO}_{2} \mathrm{nH}_{2} \mathrm{O}$, was developed to produce highstrength concrete. 
2. This reactive composition has an enhanced plasticizing effect.

3. In accordance with GOST 24211-2008 this composition refers to a plasticizer of type I.

4. When producing concrete the use of the developed reactive composition provides gain in compressive strength by $60 \%$ and an enhancement of tensile strength in bending by $75 \%$.

5. A distinguishing feature and an advantage of high-strength concrete modified by the developed complex reactive composition is increased crack resistance.

\section{References}

1. L.L. Maslennikova, M.S, Abu-Khasan, N.A. Babak, Procedia Engineering, 59-64 (2017)

2. P.G. Kmokhov, L.L. Maslennikova, M.S. Abu-Khasan, Stroitelnye materialy 12, 44 (2003)

3. L. Maslennikova, L. Svatovskaya, S. Mjakin, I. Vasiljeva, Activation of reactions at solid-solid interfaces. Improvement of ceramics materials, Electron Beam Modification of Solids: Mechanisms, Common Features and Promising Applications (2009)

4. A. Sychova, M. Sychov, E. Rusanova, Procedia Engineering 189, 681-687 (2017) DOI: 10.1016 j.proeng. 2017.05.108

5. A. Sychova, A. Solomahin, A. Hitrov, Procedia Engineering 189, 688-694 (2017) DOI: 10.1016 j.proeng. 2017.05.109

6. A. Kavetsky, G. Yakubova, M. Sychov, Q. Lin, G. Walter, D. Chan, S. Yousaf, H. Socarras, J. Abrefah, K. Bower, Nuclear Science and Engineering 159, 321-329 (2008)

7. M.M. Sychov, A.G. Kavetsky, S. Meleshkov, Conversion of radioactive decay energy to electricity Polymers, Phosphors and Voltaics for Radioisotope Microbatteries (CRC Press, 2002)

8. M. Sychov, Semiconductors 40-9, 1016-1020 (2006)

9. V. Solovyova, M. Abu-Khasan, N. Yershikov, D. Soloviev, E. Kokubin, Innovative technologies in construction and geoecology Materials of the IV International Scientific and Practical Internet Conference, 17-20 (2017)

10. V. Solovieva, M. Abu-Khasan, S. Kasatkin, N. Yershikov, D. Soloviev, Innovative technologies in construction and geoecology, Materials of the IV International Scientific and Practical Internet Conference, 21-25 (2017)

11. V. Solovyova, S. Kasatkin, I. Stepanova, L. Maslennikova, M. Abu-Khasan, N. Yorshikov, Natural and technical sciences 2 (104), 146-149 (2017)

12. V. Solovyova, L. Maslennikova, M. Abu-Khasan, I. Stepanova, N. Yorshikov, T.I. Boykova, V. Makarov, S. Kasatkin, Natural and technical sciences 2(104), 150-155 (2017)

13. V. Solovyova, L. Maslennikova, M. Abu-Khasan, I. Stepanova, T. Smirnova, T. Boykova, V. Makarov, S. Kasatkin, Natural and technical sciences 2(104), 156-162 (2017)

14. L.B. Svatovskaya, M.S. Abu-Khasan, E.V. Rusanova, New technologies for waste management (Saint-Petersburg, 2005)

15. M.S. Abu-Khasan, Natural and technical sciences 4(36), 259-265 (2008)

16. E.V. Rusanova, M.S. Abu-Khasan, Professional education, science and innovation In the XXI century collected works of the XI St. Petersburg Congress, 243-244 (2017) 
17. M.S. Abu-Khasan, E.V. Rusanova, Natural and technical Sciences 3(105), 58-65 (2017)

18. V.Y. Solovyev, M.S. Abu-Khasan, N.V. Ershikov, D.V. Soloviev, E.I. Kokubin, Innovative technologies in construction and geoecology. Materials of the IV International Scientific and Practical Internet Conference, 17-20 (2017)

19. V.Y. Solovyova, S.P. Kasatkin, I.V. Stepanova, L.L. Maslennikova, M.S. Abu-Khasan, N.V. Ershikov, Natural and technical sciences 2(104), 146-149 (2017)

20. V.Y. Solovyeva, L.L. Maslennikova, M.S. Abu-Khasan, I.V. Stepanova, N.V. Ershikov, T.I. Boykova, V.V. Makarov, S.P. Kasatkin, Natural and technical sciences 2(104), 150-155 (2017)

21. M.S. Abu-Khasan, E.V. Rusanova, Natural and technical sciences 3(105), 58-65 (2017)

22. L.B. Svatovskaya, L.G. Lukina, I.N. Stepanova, A.M. Sycheva, M.M. Baidarashvili, M.S. Abu-Khasan, Modern directions of innovative development in materials science, nanosystems (St. Petersburg, 2016)

23. L.L. Maslennikova, V.Y. Solovyova, I.V. Stepanova, V.E. Ivanova, A.N. Troshev, I.A. Naginsky, M.S. Abu-Khasan, Features of the processes of artificial stone formation and raw materials in obtaining materials (St. Petersburg, 2016) 